\title{
Gait analysis and functional outcome in patients after Lisfranc injury treatment
}

Citation for published version (APA):

van Hoeve, S., Stollenwerck, G., Willems, P., Witlox, M. A., Meijer, K., \& Poeze, M. (2018). Gait analysis and functional outcome in patients after Lisfranc injury treatment. Foot and Ankle Surgery, 24(6), 535-541. https://doi.org/10.1016/j.fas.2017.07.003

Document status and date:

Published: 01/12/2018

DOI:

10.1016/j.fas.2017.07.003

Document Version:

Publisher's PDF, also known as Version of record

Document license:

Taverne

Please check the document version of this publication:

- A submitted manuscript is the version of the article upon submission and before peer-review. There can be important differences between the submitted version and the official published version of record.

People interested in the research are advised to contact the author for the final version of the publication, or visit the DOI to the publisher's website.

- The final author version and the galley proof are versions of the publication after peer review.

- The final published version features the final layout of the paper including the volume, issue and page numbers.

Link to publication

\footnotetext{
General rights rights.

- You may freely distribute the URL identifying the publication in the public portal. please follow below link for the End User Agreement:

www.umlib.nl/taverne-license

Take down policy

If you believe that this document breaches copyright please contact us at:

repository@maastrichtuniversity.nl

providing details and we will investigate your claim.
}

Copyright and moral rights for the publications made accessible in the public portal are retained by the authors and/or other copyright owners and it is a condition of accessing publications that users recognise and abide by the legal requirements associated with these

- Users may download and print one copy of any publication from the public portal for the purpose of private study or research.

- You may not further distribute the material or use it for any profit-making activity or commercial gain

If the publication is distributed under the terms of Article $25 \mathrm{fa}$ of the Dutch Copyright Act, indicated by the "Taverne" license above, 


\title{
Gait analysis and functional outcome in patients after Lisfranc injury treatment
}

\author{
S. van Hoeve ${ }^{\mathrm{a}, *}$, G. Stollenwerck ${ }^{\mathrm{a}}$, P. Willems ${ }^{\mathrm{b}, \mathrm{c}}$, M.A. Witlox $^{\mathrm{d}}$, K. Meijer $^{\mathrm{b}, \mathrm{c}}$, M. Poeze $^{\mathrm{a}, \mathrm{c}}$ \\ a Department of Surgery, Division of Trauma Surgery, Maastricht University Medical Center, P. Debyelaan 25, P.0. Box 5800, 6202 AZ Maastricht, The \\ Netherlands \\ ${ }^{\mathbf{b}}$ Department of Movement Sciences, Maastricht University Medical Center, P. Debyelaan 25, P.0. Box 616, 6200 MD Maastricht, The Netherlands \\ c NUTRIM, School for Nutrition, Toxicology and Metabolism, P.O. Box 616, 6200 MD Maastricht, The Netherlands \\ ${ }^{\mathrm{d}}$ Department of Orthopaedics, Maastricht University Medical Center, P. Debyelaan 25, P.O. Box 616, 6200 MD Maastricht, The Netherlands
}

\section{A R T I C L E I N F O}

\section{Article history:}

Received 5 February 2017

Received in revised form 4 July 2017

Accepted 5 July 2017

Keywords:

Gait

Lisfranc injury

Follow-up

Range of motion

Biomechanics

\begin{abstract}
A B S T R A C T
Introduction: Lisfranc injuries involve any bony or ligamentous disruption of the tarsometatarsal joint. Outcome results after treatment are mainly evaluated using patient-reported outcome measures (PROM), physical examination and radiographic findings. Less is known about the kinematics during gait. Methods: Nineteen patients ( 19 feet) treated for Lisfranc injury were recruited. Patients with conservative treatment and surgical treatment consisting of open reduction and internal fixation (ORIF) or primary arthrodesis were included. PROM, radiographic findings and gait analysis using the Oxford Foot Model (OFM) were analysed. Results were compared with twenty-one healthy subjects ( 31 feet). Multivariable logistic regression was used to determine factors influencing outcome.

Results: Patients treated for Lisfranc injury had a significantly lower walking speed than healthy subjects $(\mathrm{P}<0.001)$. There was a significant difference between the two groups regarding the range of motion $(\mathrm{ROM})$ in the sagittal plane (flexion-extension) in the midfoot durieng the push-off phase $(\mathrm{p}<0.001)$. The ROM in the sagittal plane was significantly correlated with the AOFAS midfoot score $\left(r^{2}=0.56, p=0.012\right)$, FADI $\left(r^{2}=0.47, p=0.043\right)$ and the SF-36-physical impairment score $\left(r^{2}=0.60, p=0.007\right)$ but not with radiographic parameters for quality of reduction. In a multivariable analysis, the best explanatory factors were ROM in the sagittal plane during the push-off phase $(\beta=0.707, \mathrm{p}=0.001)$, stability $(\beta=0.423$, $\mathrm{p}=0.028)$ and BMI $(\beta=-0.727 \mathrm{p}=<0.001)$. This prediction model explained $87 \%$ of patient satisfaction. Conclusions: This study showed that patients treated for Lisfranc injury had significantly lower walking speed and significantly lower flexion/extension in the midfoot than healthy subjects. The ROM in these patients was significantly correlated with PROM, but not with radiographic quality of reduction. Most important satisfaction predictors were BMI, ROM in the sagittal plane during the push-off phase and fracture stability.
\end{abstract}

(c) 2017 European Foot and Ankle Society. Published by Elsevier Ltd. All rights reserved.

\section{Introduction}

Lisfranc injuries involve any bony or ligamentous disruption of the tarsometatarsal joint complex. This injury is not very common, with $0.2 \%$ of all fractures [1-4]. The outcome of Lisfranc injury is determined by the extent of soft tissue damage, bone injury and the presence or absence of instability in the tarsometatarsal joint. Other important determinants of good prognosis include early successful identification of instability and treatment [5-7]. Outcome results after treatment of Lisfranc injuries have mainly been evaluated using patient-reported outcome measures (PROM),

\footnotetext{
* Corresponding author.

E-mail address: s.vanhoeve@student.maastrichtuniversity.nl (S. van Hoeve).
}

physical examination and radiographic findings [8,9]. Less is known about the biomechanical changes after Lisfranc injury. One study analysed 24 patients, including 6 patients with a Lisfranc fracture, using PROM, pedobarographic analysis and radiographic examinations. They found significantly lower walking speed in patients after Lisfranc injury treatment compared to a group of healthy subjects [3].

Multi-segment foot models (MSFM) are available for analysing kinematic parameters during gait [10-29]. The four-segment Oxford foot model (OFM) is described as being a reliable model $[15,18,27,30,31]$. Intersegment rang of motion (ROM) during gait was previously found to be related to PROM in patients with foot and ankle trauma [32]. Hence, kinematic gait analysis could provide more insight into kinematic changes in patients after Lisfranc injury and in addition could lead to more information on 
unsolved issues such as the influence on surgical reduction on functional outcome and the best fixation method [4,33-39].

The aim of this study was to investigate kinematic parameters of the foot and ankle in a group of patients after bony Lisfranc injury and to compare these with healthy subjects. The kinematic results were further correlated with PROM and quality of reduction. In addition, a multivariable logistic regression analysis was performed to determine factors explaining patient satisfaction. The hypothesis was that patients who suffer bony Lisfranc injury would show decreased ROM (flexion/extension) in the midfoot compared to healthy subjects and that kinematics during gait would significantly correlate with PROM and the quality of surgical reduction.

\section{Methods}

\subsection{Study population}

For this prospective observational study (Level II evidence), 19 patients ( 19 feet) treated for bony Lisfranc injury were recruited. The medical ethics committee of this hospital approved this study, and all study subjects gave written informed consent. All patients underwent computed tomography to determine the extent of the bony Lisfranc injury and were taken to the operating room for fluoroscopic testing of the stability of the Lisfranc joint. If this was stable, patients were treated with cast immobilization. If this was unstable, patients underwent ORIF with plate-screw osteosynthesis, or arthrodesis, depending on the type of fracture, comminution and bone quality. This decision was made by an experienced trauma surgeon. After 8 weeks, full weight bearing was allowed and supported by physiotherapy. Hardware was removed at least 6 months after operation when patients reported complaints about the screws and/or plates. The researcher contacted the patients six months after their initial treatment, as gait studies have shown that most motion progress after fracture treatment takes place between 3 and 6 months after surgery $[40,41]$. Recruited patients were then enrolled for gait analysis if they had returned to their normal daily lives as before the injury and had minimal complaints related to the injury. Exclusion criteria were simultaneous surgery for fractures of thecontralateral leg/ankle or pre-existent abnormalities of the lower extremities, neurotrauma, spinal or neurological injury and pathologic fractures. The age was set between 25 and 70 years, since age has limited influence on gait [42-44]. Walking speed and kinematic results were compared with those of 21 healthy subjects ( $n=21,31$ feet) without any traumatic lower extremity injury, who had been randomly recruited applying the same exclusion criteria as for the patients with bony Lisfranc injury. In 10 patients both legs were analysed to exclude a possible influence of foot dominance.

\subsection{Equipment}

Motion capture was conducted using the VICON MX 3-system (Vicon Motion Systems Ltd., Oxford, UK). The VICON system comprises eight cameras (6 MX3 and $2 \mathrm{~T} 20$, running at $200 \mathrm{~Hz}$ ) connected to a computer for detection of markers placed on the skin of both legs. The markers were placed on specific anatomic landmarks on the subjects using regular double-sided tape, according to the guidelines for the OFM [15,18,27]. One force plate (Kistler 9282E) was used to analyse gait during walking. A 10-m catwalk was used for walking to provide a normal walking pattern. Vicon NEXUS was used to visualize 3D animation motions.

\subsection{Study protocol}

All subjects were analysed at the movement laboratory separately. Before gait analysis, the following characteristics were measured: height, weight, body mass index (BMI $\left(\mathrm{kg} / \mathrm{m}^{2}\right)$ ), leg length, knee and ankle width. One researcher who had been trained in the examination of the foot and ankle and the OFM, performed all measurements according the protocol described in previous studies $[30,32,44]$. Patients and healthy subjects were asked to walk at self-selected normal, slow and fast speed. The data of one whole step (initial contact to toe-off) was divided into two intervals: loading phase (initial contact - midstance) and push-off phase (midstance - toe-off). Walking speed and intersegment ROM between forefoot-hindfoot and hindfoottibia were calculated in the frontal, sagittal and transverse planes (representing abduction/adduction, flexion/extension, and inversion/eversion, respectively) $[45,46]$. For patients with bony Lisfranc injury, the following data was collected: baseline data from the case record form completed at hospital admission, PROM at the time of gait analysis (American orthopaedic foot and ankle society midfoot score [AOFAS]; foot and ankle disability index [FADI]; Short-Form 36 score [SF-36]; visual analogue pain scale [VAS], with maximum pain, minimum pain and pain at moment of gait analysis ranging from 0 to 10), radiographic findings and OFM gait analysis. Six months postoperatively, computed tomography scans and plain X-rays were made to analyse the quality of surgical reduction. These measurements were performed by one experienced investigator blinded for the kinematic and PROM results. The quality of reduction was determined by measuring the space between the first and second metatarsal bones, and the second and third metatarsal bones, on the weight bearing dorsal-plantar radiographs. The calcaneal pitch was also measured, between a line from the first metatarsal to the calcaneal bone and a line under de calcaneal bone, on weight bearing lateral radiographs. The talometatarsal angle was measured between the talus and the first metatarsal bone, on weight bearing dorsal-plantar radiographs $[36,47]$.

\subsection{Data analysis}

Prospective power was calculated with alpha set at 0.05 and beta at 0.80 , using a sample size calculation tool [48]. The ROM value between forefoot and hindfoot segments in the sagittal plane in healthy subjects was estimated to be $15.0^{\circ}$ (SD 3.0). The expected clinically significant decrease in ROM in patients after bony Lisfranc injury was expected to be at least $12.0^{\circ}$, more than one standard deviation [30]. The number of included patients was set to a minimum of 8 patients for each group.

Kinematic data was processed with Matlab (version 7.12,2011) and statistical analysis was performed in SPSS (IBM Statistics, version 20). The data comprised of six trials (steps) randomly chosen. The characteristics were analysed using descriptive statistics and the independent samples t-test for differences; a p-value below 0.05 was considered to be statistically significant. Kinematic results were correlated with PROM and the parameters of quality of reduction. The Pearson correlation coefficient was calculated to identify correlations. A multivariable logistic regression analysis was performed using the enter method and the backward method, with the following factors: American Society of Anaesthesiologists physical status classification system (ASA), age, BMI, kinematic parameters, fixation method, fracture stability (as seen peroperatively) and quality of reduction, to explain patient satisfaction as assessed by PROM (AOFAS and FADI). 


\section{Results}

\subsection{Patient characteristics}

Table 1 presents the baseline characteristics for the patients treated for a bony Lisfranc injury, and for the healthy subjects. There were no significant differences between the two groups regarding age, left or right foot being analysed, weight, leg length, knee width or ankle width. In the bony Lisfranc group, there were significantly more women, patients had a lower length and had a higher BMI compared to healthy subjects. Gait analysis was performed at a mean of 17 months (median 11, range 6-52) after treatment. No significant correlation was found between the moment of gait analysis after treatment and the ROM in the sagittal plane (flexion/extension) during the loading and push-off phases (Pearson-test $\mathrm{r}^{2}=0.317, \mathrm{p}=0.187$ and $r^{2}=0.064, p=0.794$ respectively).

Trauma mechanism was traffic accident in 4 patients, fall from height in 1 patient, work accident in 2 patients and a low-energy trauma in 12 patients. No patients with a purely ligamentous injury were included. Overall, 5 patients (26.3\%) had a stable Lisfranc fracture pattern and were treated conservatively with cast, while 8 patients $(42.1 \%)$ underwent ORIF with plate and screw osteosynthesis for instability and 6 patients (31.6\%) underwent arthrodesis. Only two patients in the ORIF group underwent removal of hardware before gait analysis. Postoperatively, 1 patient (7.1\%) developed a deep infection for which surgical wound debridement was required as well as intravenous antibiotics. None of the patients needed revision surgery. Six months postoperatively, 13 of the 16 patients $(81 \%)$ had returned to their previous work, while the other 3 patients had not been in work before their injury.

\subsection{Gait analysis}

Table 2 shows the walking speed and intersegment ROM between forefoot and hindfoot for patients with a bony Lisfranc
Table 1

Patient characteristics.

\begin{tabular}{llll}
\hline Group & $\begin{array}{l}\text { Lisfranc injury } \\
19\end{array}$ & $\begin{array}{l}\text { Healthy control } \\
21,31 \text { feet }\end{array}$ & p-Value \\
\hline Age (years) & $40.5 \pm 16.7(18-68)$ & $35.8 \pm 17.6(20-65)$ & 0.389 \\
Gender (n, \% male) & $7,36.8 \%$ & $18,85.7 \%$ & $\mathbf{0 . 0 0 1}$ \\
Side (n,\% right) & $8,42.1 \%$ & $20,64.5 \%$ & 0.408 \\
Height (m) & $1.71 \pm 0.1(1.54-1.85)$ & $1.79 \pm 0.06(1.69-1.88)$ & $\mathbf{0 . 0 0 4}$ \\
Weight (kg) & $81.3 \pm 20.9(47-122)$ & $75.0 \pm 10.0(62-91)$ & 0.234 \\
BMI & $27.5 \pm 5.7(19.8-39.4)$ & $23.3 \pm 2.7(19.4-29.1)$ & $\mathbf{0 . 0 0 7}$ \\
Knee width (mm) & $105 \pm 12.25(81-130)$ & $104.1 \pm 6.8(93-120)$ & 0.634 \\
Ankle width (mm) & $65.8 \pm 5.1(57-77)$ & $69.5 \pm 4.9(62-80)$ & 0.083 \\
Leg length (mm) & $888.7 \pm 55.3(790-$ & $923.4 \pm 43.8(780-$ & 0.107 \\
& $980)$ & $970)$ & \\
\hline
\end{tabular}

Results are presented as mean \pm standard deviation (min-max) (independentsamples t-test).

Bold are the significant differences.

injury and healthy subjects. The patients treated for bony Lisfranc injury had a significantly lower walking speed compared to the healthy subjects when asked to walk at normal speed (t-test $\mathrm{p}<0.001$ ). When healthy subjects were asked to walk at slow speed, there was no significant difference between the two groups, and further analyses were performed with these results $(\mathrm{p}=0.798)$.

Regarding ROM between hindfoot and forefoot, there was a significantly lower ROM in the Lisfranc group in the sagittal plane (flexion/extension) during the push-off phase (t-test $\mathrm{p}<0.001$ ), but this was not found during the loading phase (t-test $\mathrm{p}=0.292$ ). There was also a significant difference in ROM between the two groups in the frontal plane (abduction/adduction) during the pushoff phase ( $\mathrm{t}$-test $\mathrm{p}=0.001$ ), but not during the loading phase ( $\mathrm{t}$-test $\mathrm{p}=0.407$ ). In the transverse plane (inversion/eversion) there was a significant difference between the two groups during both the loading and push-off phases (t-test $\mathrm{p}<0.001$ and $\mathrm{p}=0.018$, respectively; Figs. 1 and 2).

In Table 3 the ROM between hindfoot and tibia in patients after bony Lisfranc injury treatment compare with healthy subjects is presented. Patients after bony Lisfranc injury showed significantly

Table 2

Speed and inter-segment range of motion between forefoot and hindfoot.

\begin{tabular}{|c|c|c|c|}
\hline Variables & Groups & & p-Value \\
\hline \multirow{4}{*}{ Speed (m/s) } & \multirow{2}{*}{ Lisfranc } & Healthy subjects & Lisfranc vs healthy subjects \\
\hline & & Normal & Normal Slow \\
\hline & $0.92 \pm 0.24(0.38-1.30)$ & $0.940 .20(0.54-1.23)$ & $<0.001$ \\
\hline & Lisfranc & Healthy subjects in (slow speed) & Lisfranc vs healthy subjects \\
\hline \multicolumn{4}{|c|}{ Forefoot-hindfoot loading phase } \\
\hline $\begin{array}{l}\text { Sagittal plane } \\
\text { Flexion/extension } \\
\text { (degree) }\end{array}$ & $\mathbf{7 . 0 6} \pm 2.48(2.31-12.25)$ & $\mathbf{7 . 8 0} \pm 2.33(4.27-12.88)$ & 0.292 \\
\hline $\begin{array}{l}\text { Frontal plane } \\
\text { Abduction/adduction } \\
\text { (degree) }\end{array}$ & $4.21 \pm 1.93(1.84-9.11)$ & $\mathbf{4 . 6 1} \pm 1.40(2.19-7.83)$ & 0.407 \\
\hline $\begin{array}{l}\text { Transverse plane } \\
\text { Inversion/eversion } \\
\text { (degree) }\end{array}$ & $\mathbf{5 . 4 9} \pm 2.16(2.51-10.12)$ & $\mathbf{7 . 6 6} \pm 1.87(3.49-11.61)$ & $<\mathbf{0 . 0 0 1}$ \\
\hline \multicolumn{4}{|c|}{ Forefoot-hindfoot push-off phase } \\
\hline $\begin{array}{l}\text { Sagittal plane } \\
\text { Flexion/extension } \\
\text { (degree) }\end{array}$ & $\mathbf{1 1 . 5 5} \pm 4.79(5.09-23.17)$ & $\mathbf{1 6 . 6 1} \pm 3.52(8.15-23.72)$ & $<\mathbf{0 . 0 0 1}$ \\
\hline $\begin{array}{l}\text { Frontal plane } \\
\text { Abduction/adduction } \\
\text { (degree) }\end{array}$ & $\mathbf{6 . 8 3} \pm 2.56(2.74-12.06)$ & $\mathbf{9 . 8 1} \pm 2.96(3.95-17.31)$ & 0.001 \\
\hline $\begin{array}{l}\text { Transverse plane } \\
\text { Inversion/eversion } \\
\text { (degree) }\end{array}$ & $7.52 \pm 2.24(4.32-11.73)$ & $\mathbf{8 . 9 3} \pm 1.82(5.36-12.63)$ & 0.018 \\
\hline
\end{tabular}

Results are presented as mean with \pm standard deviation and (minimum-maximum) (independent-samples t-test).

Bold are the significant differences. 


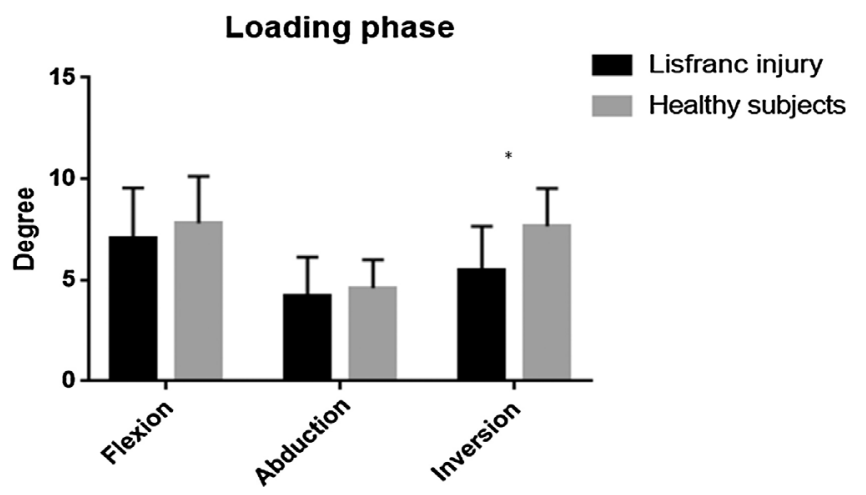

Fig. 1. Range of motion in the sagittal, frontal and transverse planes during the loading phase for patients treated for bony Lisfranc injury and healthy subjects.

lower ROM in the sagittal plane (flexion/extension) during the push-off phase ( $\mathrm{t}$-test $\mathrm{p}=0.040$ ). In contrast, the ROM in the frontal plane (abduction/adduction) during the push-off phase was significantly higher in the patients with a bony Lisfranc injury than in the healthy subjects (t-test $\mathrm{p}=0.001$ )

\subsection{Gait correlated with PROM and radiographic findings}

The ROM between the forefoot and hindfoot during the push-off phase in the sagittal plane (flexion/extension) was significantly correlated with PROM as defined by the AOFAS midfoot score (Pearson test $\mathrm{r}^{2}=0.56, \mathrm{p}=0.01$ ), the FADI (Pearson test $\mathrm{r}^{2}=0.47$, $\mathrm{p}=0.04$ ), the SF-36-physical impairment score (Pearson test $\left.r^{2}=0.60, p=0.007\right)$ and the VAS score at the moment of walking (Pearson test $\mathrm{r}^{2}=-0.54, \mathrm{p}=0.02$ ). (Table 4) No significant correlations were found between the radiographic findings for quality of reduction, PROM and kinematic parameters.

\subsection{Multivariable logistic regression analysis}

In a multivariable logistic regression analysis, ASA, age, BMI, kinematic parameters, fixation method and fracture stability per-

\section{Push-off phase}

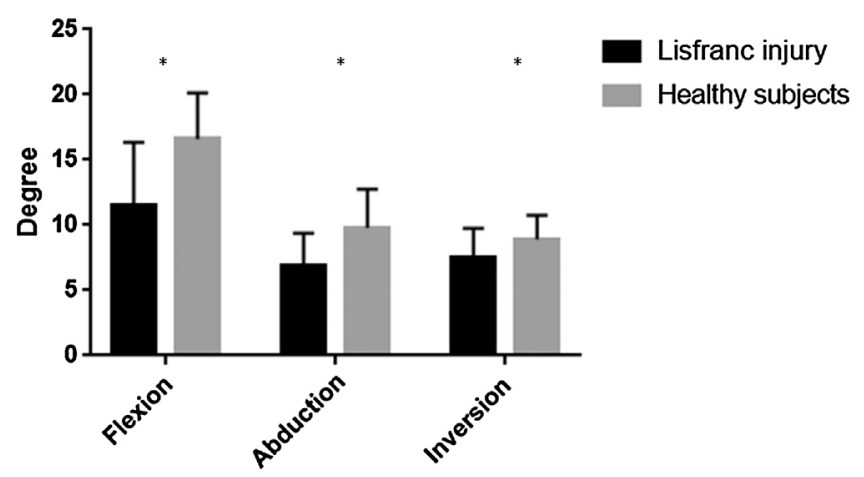

Fig. 2. Range of motion in the sagittal, frontal and transverse planes during the push-off phase for patients treated for bony Lisfranc injury treatment and healthy subjects.

operatively and quality of reduction were tested as predictors of patient satisfaction reported as the AOFAS ankle midfoot score and FADI. Using the AOFAS as the patient satisfaction outcome parameter, $87 \%$ of patients' satisfaction could be explained using these factors in this predictive model. Best explanatory factors were ROM in the sagittal plane during the push-off phase $(\beta=0.707, \quad \mathrm{p}=0.001), \quad$ stability (as seen per-operatively) $(\beta=0.423, \mathrm{p}=0.028)$ and BMI $(\beta=-0.727 \mathrm{p}=<0.001)$. Using the FADI as the patient satisfaction outcome parameter, $71 \%$ of patients' satisfaction could be explained by these factors. Best explanatory factors were ROM in the sagittal plane during the push-off phase $(\beta=0.411, \mathrm{p}=0.057)$ and $\mathrm{BMI}(\beta=-0.463$, $\mathrm{p}=0.035$ ).

\section{Discussion}

The present study reveals a more detailed analysis of kinematic changes in foot and ankle after bony Lisfranc injury by using a MSFM. This study found that patients who had suffered Lisfranc injury had significantly lower walking speed and significantly

Table 3

Speed and inter-segment range of motion between hindfoot and tibia.

\begin{tabular}{|c|c|c|c|c|}
\hline Variables & Groups & & & p-Value \\
\hline & Lisfranc & Healthy subjects & & Lisfranc vs healthy subjects \\
\hline & & Normal & Slow & Normal \\
\hline \multirow[t]{2}{*}{ Speed $(\mathrm{m} / \mathrm{s})$} & $0.92 \pm 0.24(0.38-1.30)$ & $1.220 .19(0.89-1.59)$ & $0.940 .20(0.54-1.23)$ & $\begin{array}{ll}<0.001 \quad 0.798\end{array}$ \\
\hline & Lisfranc & Healthy subjects & & Lisfranc vs healthy subjects (compensated for speed) \\
\hline \multicolumn{5}{|c|}{ Hindfoot-tibia loading phase } \\
\hline $\begin{array}{l}\text { Sagittal plane } \\
\text { Flexion/extension } \\
\text { (degree) }\end{array}$ & $\mathbf{1 0 . 2 5} \pm 3.16(4.09-15.65)$ & $\mathbf{1 0 . 0 9} \pm 2.65(3.86-14.78)$ & & 0.847 \\
\hline $\begin{array}{l}\text { Frontal plane } \\
\text { Abduction/adduction } \\
\text { (degree) }\end{array}$ & $\mathbf{1 4 . 2 1} \pm 5.61(7.34-29.68)$ & $12.07 \pm 3.11(6.85-18.09)$ & & 0.089 \\
\hline $\begin{array}{l}\text { Transverse plane } \\
\text { Inversion/eversion } \\
\text { (degree) }\end{array}$ & $7.83 \pm 6.29(2.76-31.13)$ & $\mathbf{6 . 2 9} \pm 1.92(2.95-11.21)$ & & 0.310 \\
\hline \multicolumn{5}{|c|}{ Hindfoot-tibia push-off phase } \\
\hline $\begin{array}{l}\text { Sagittal plane } \\
\text { Flexion/extension } \\
\text { (degree) }\end{array}$ & $\mathbf{9 . 9 7} \pm 3.46(4.26-16.45)$ & $\mathbf{1 2 . 0 9} \pm 3.42(5.32-18.35)$ & & 0.040 \\
\hline $\begin{array}{l}\text { Frontal plane } \\
\text { Abduction/adduction } \\
\text { (degree) }\end{array}$ & $\mathbf{1 5 . 3 3} \pm 6.11(7.61-30.04)$ & $\mathbf{1 0 . 4 8} \pm 4.07(5.68-27.25)$ & & 0.001 \\
\hline $\begin{array}{l}\text { Transverse plane } \\
\text { Inversion/eversion } \\
\text { (degree) }\end{array}$ & $\mathbf{9 . 5 7} \pm 4.47(2.92-18.07)$ & $\mathbf{9 . 7 5} \pm 3.49(4.94-17.89)$ & & 0.875 \\
\hline
\end{tabular}

Results are presented as mean with \pm standard deviation and (minimum-maximum) (independent-samples t-test).

Bold are the significant differences. 
Table 4

Correlations between range of motion, patient reported outcome measures and quality of reduction in patients after Lisfranc injury.

\begin{tabular}{|c|c|c|c|c|c|c|}
\hline & $\begin{array}{l}\text { Range of motion sagittal } \\
\text { plane loading phase }\end{array}$ & $\begin{array}{l}\text { Range of motion sagittal plane } \\
\text { push-off phase }\end{array}$ & AOFAS & FADI & VAS & $\begin{array}{l}\text { SF-36 physical } \\
\text { impairment }\end{array}$ \\
\hline Range of motion sagittal plane loading phase & - & 0.562 & 0.089 & 0.079 & -0.068 & 0.186 \\
\hline Range of motion sagittal plane push-off phase & 0.562 & - & $0.563^{*}$ & 0.468 & $-0.543^{*}$ & $0.595^{* *}$ \\
\hline space between first and second metatarsal & -.131 & -0.071 & 0.001 & -0.046 & -0.186 & 0.030 \\
\hline space between second and third metatarsal & 0.231 & 0.081 & 0.053 & 0.019 & 0.124 & 0.052 \\
\hline
\end{tabular}

Correlation coefficients by Pearson.

Bold are the significant differences.

Significant level 0.05 .

*** Significant level 0.01 .

decreased flexion/extension in the midfoot during the push-off phase. In addition, this ROM was significantly correlated with PROM but not with the radiographic quality of reduction.

A limited number of studies have analysed gait in patients with Lisfranc injuries. In a study by Kösters et al., 24 patients with foot fractures, including 6 patients with a Lisfranc fracture, were examined with PROM, pedobarographic analysis and radiographic examinations. They found significant lower walking speed in patients treated for Lisfranc injury, just as found in our study. However, they did not analyse the ROM in the forefoot [3]. Teng et al. evaluated 11 patients with unilateral closed Lisfranc fracture dislocation. They used physical examination, radiographic analysis of anatomic reduction and gait analysis with an in-shoe pressure monitoring system, analysing vertical ground reaction force under the hallux, first metatarsal head, lateral metatarsals and heel [33]. They found no abnormalities in vertical ground reaction forces in patients after Lisfranc injury compared with the contralateral foot, and they found no relation between these parameters and the radiographic evaluated reduction of the Lisfranc injury. We could not find a significant correlation between quality of reduction and outcome in terms of kinematic parameters and patient satisfaction. Wiss et al. analysed 23 patients with Lisfranc fracture dislocation using PROM, physical examination and radiographic analysis [34]. Gait analysis was performed in a subgroup of 11 patients, analysing time of stance. They found best results, both clinically and in gait analysis, for patients who had an anatomic reduction of the dislocation. We found that altered gait in patients with a bony Lisfranc injury is mainly caused by an abnormal flexion-extension movement between the hindfoot and forefoot. This may also explain the prolonged hindfoot period, and a delayed and shortened period of weight transfer through the midfoot to the forefoot in the study by Wiss et al. [35].

Regarding the clinical impact of this study. This study showed that patients after Lisfranc injury have altered gait compared with healthy subjects. We found that altered gait in patients with a Lisfranc injury is mainly caused by a limited flexion-extension movement between the hindfoot and forefoot, while this was significantly correlated with PROM. This indicates that in the postoperative phase a high flexion-extension motion is important for patient satisfaction. However not the primary aim of this study, when analysing our kinematic results between patients treated with cast or ORIF or a primary arthrodesis, multiple differences were found (Table 5). Best kinematic and PROM results were found for patients treated with cast for stable Lisfranc fractures compared with the other two techniques. This result seems obvious as fixation of a joint as performed in the ORIF and arthrodesis group

Table 5

Outcome in Lisfranc injury group by treatment for speed and inter-segment range of motion.

\begin{tabular}{|c|c|c|c|c|c|c|}
\hline \multirow[t]{2}{*}{ Variables } & \multicolumn{3}{|l|}{ Groups } & \multicolumn{3}{|l|}{ p-Value } \\
\hline & $\begin{array}{l}\text { Conservative } \\
\mathrm{N}=5\end{array}$ & $\begin{array}{l}\text { ORIF } \\
N=8\end{array}$ & $\begin{array}{l}\text { Arthrodesis } \\
\mathrm{N}=6\end{array}$ & $\begin{array}{l}\text { Conservative } \\
\text { vs ORIF }\end{array}$ & $\begin{array}{l}\text { Conservative vs } \\
\text { arthrodesis }\end{array}$ & $\begin{array}{l}\text { ORIF vs } \\
\text { arthrodesis }\end{array}$ \\
\hline Speed (m/s) & $0.86 \pm 0.24(0.53-1.13)$ & $0.98 \pm 0.22(0.67-1.30)$ & $0.90 \pm 0.30(0.38-1.21)$ & 0.385 & 0.838 & 0.566 \\
\hline \multicolumn{7}{|c|}{ Forefoot-hindfoot loading phase } \\
\hline $\begin{array}{l}\text { Sagittal plane } \\
\text { Flexion/extension } \\
\text { degree }\end{array}$ & $8.90 \pm 2.31(6.40-12.25)$ & $6.13 \pm 1.23(3.40-7.40)$ & $\mathbf{6 . 7 8} \pm 3.31(2.31-11.83)$ & 0.015 & 0.257 & 0.664 \\
\hline $\begin{array}{l}\text { Frontal plane } \\
\text { Abduction/adduction } \\
\text { degree }\end{array}$ & $\mathbf{3 . 2 9} \pm 0.98(2.29-4.86)$ & $\mathbf{5 . 5 8} \pm 1.98(3.52-9.11)$ & $\mathbf{3 . 1 5} \pm 1.40(1.84-4.99)$ & 0.036 & 0.850 & 0.025 \\
\hline $\begin{array}{l}\text { Transverse plane } \\
\text { Inversion/eversion } \\
\text { degree }\end{array}$ & $\mathbf{3 . 2 9} \pm 0.98(2.29-4.86)$ & $5.39 \pm 2.81(2.51-10.12)$ & $\mathbf{3 . 1 5} \pm 1.40(1.84-4.99)$ & 0.596 & 0.294 & 0.792 \\
\hline \multicolumn{7}{|c|}{ Forefoot-hindfoot push-off phase } \\
\hline $\begin{array}{l}\text { Sagittal plane } \\
\text { Flexion/extension } \\
\text { degree }\end{array}$ & $16.28 \pm 5.45(8.00-23.17)$ & $\mathbf{9 . 2 9} \pm 1.46(7.79-11.50)$ & $\mathbf{1 0 . 6 1} \pm 4.91(5.09-18.95)$ & 0.005 & 0.103 & 0.481 \\
\hline $\begin{array}{l}\text { Frontal plane } \\
\text { Abduction/adduction } \\
\text { degree }\end{array}$ & $\mathbf{9 . 2 6} \pm 2.08(6.23-12.06)$ & $6.73 \pm 2.30(3.70-11.04)$ & $4.94 \pm 1.59(2.74-6.40)$ & 0.071 & 0.004 & 0.129 \\
\hline $\begin{array}{l}\text { Transverse plane } \\
\text { Inversion/eversion } \\
\text { degree }\end{array}$ & $\mathbf{8 . 2 5} \pm 2.27(4.87-10.61)$ & $6.81 \pm 2.11(4.32-9.90)$ & $7.85 \pm 2.50(4.98-11.73)$ & 0.270 & 0.792 & 0.413 \\
\hline \multicolumn{7}{|l|}{ Questionnaires } \\
\hline FADI & $\mathbf{8 9 . 0} \pm 11.6(76.0-100)$ & $72.0 \pm 19.5(40.4-92.3)$ & $\mathbf{7 0 . 0} \pm 17.1(52.9-100)$ & 0.107 & 0.065 & 0.846 \\
\hline AOFAS & $\mathbf{8 3 . 0} \pm 15.0(68.0-100.0)$ & $72.5 \pm 13.5(43.0-85.0)$ & $\mathbf{6 5 . 5} \pm 17.7(54.0-98.0)$ & 0.216 & 0.115 & 0.416 \\
\hline
\end{tabular}

Results are presented as mean with \pm standard deviation and (minimum-maximum) (independent-samples t-test).

Bold are the significant differences. 
limits motion of the joint. Interestingly, 2 patients in the ORIF group had removal of their hardware before gait analysis. The results of these two patients showed no significant higher ROM and PROM results compared to the other patients with ORIF with hardware in situ.

In addition, our multivariable logistic regression analysis found the presence of per-operatively stability to be an important explanatory factor for outcome, while the predictive value of the degree of reduction was very low. These results indicate that it is not the quality of reduction but the stability of the Lisfranc joint found during operation which is a major explanatory factor for the outcome of Lisfranc injury. As seen in the results per treatment group, patients with stable Lisfranc fractures, found per operatively, had best PROM and kinematic results. Patients with fixation, because of instability of the fracture, showed lower ROM and lower satisfaction. Also, patients with hardware removal showed lower ROM and kinematic results compared to patients with stable injuries. This indicates that the severity of the fracture with as a consequence instability is important for outcome.

The ideal treatment for Lisfranc injuries for achieving and maintaining alignment in the midfoot is under debate. Some studies favor open reposition and fixation $[4,35,37]$. Other studies state that an arthrodesis is the best primary treatment option $[9,39]$. Comparing the ORIF and primary arthrodesis results, we found only a significantly lower abduction/adduction ROM between forefoot and hindfoot during loading phase in the patients after arthrodesis. PROM results were comparable. By excluding the results of patients with hardware removal in the ORIF group no other significant differences were found between patients with ORIF and primary arthrodesis regarding kinematics and PROM results.

Patients treated for bony Lisfranc injury were found to have a greater ROM between the hindfoot and tibia in the frontal plane during the push-off phase leading to more exorotation of the foot. This may suggest a compensation mechanism for the lack of ROM in the sagittal plane (flexion/extension) between the forefoot and hindfoot. Interestingly, this compensation mechanism was not situated between the forefoot and hindfoot but between the hindfoot and tibia (ankle). There was no correlation between this compensatory motion and patient satisfaction and radiographic quality of reduction.

A number of comments need to be made on the interpretation of the observations in our study. Our primary aim was to find kinematic differences in patients after bony Lisfranc injury compared to healthy subjects. The group of 19 patients has a wide range of presentations as can be seen in the clinical situation and therefore is a highly generalizable group. The strength of this study is the widespread in range of motion (flexion/extension) found in patients after bony Lisfranc injury and the correlation with PROM. Some patients with stable injuries showed higher range of motion comparable with range of motion of healthy subjects and scored significantly higher scores in PROM while others with more severe injury showed lower range of motion and had lower scores in PROM. This study can be used for upcoming studies to compare different treatment options. Secondly, the OFM does not allow for direct measurement of the motion in the Lisfranc joint. The OFM is a validated technique to estimate intersegment motions of the foot and ankle [30]. It can measure the ROM between the forefoot and hindfoot, including both the Chopart and Lisfranc joints, but does not provide a direct ROM between the metatarsal and cuneiform bones. This means that the reduced motion found in this study includes both the (injured) Lisfranc joint and the Chopart joint, which can give additional compensatory decreased ROM. Thirdly, a remark has to be made on the results found in Table 5 where the three different treatment options were compared. There was a limited number of patients in each group. Regarding hardware removal only 2 patients were analysed. Therefore, more research is warranted for the influence of hardware on gait in patients after Lisfranc injury.

\section{Conclusion}

This study showed that patients who had suffered bony Lisfranc injury had significantly lower walking speed and significantly lower flexion/extension in the midfoot compared to healthy subjects during the push-off phase. Compensation was found in the ankle joint leading to more exorotation in the foot in patients after Lisfranc injury with lower flexion/extension. The ROM significantly correlated with the patient satisfaction reported in the AOFAS, FADI, SF-36 physical impairment and VAS, but not with the radiographic quality of surgical reduction. Important explanatory factors for patient satisfaction as assessed by PROM were the ROM in the sagittal plane during the push-off phase and the fracture stability.

\section{Ethics approval and consent to participate}

This study was approved by the medical ethical board of AZM/ UM Maastricht.

NL 34131.068.10/MEC 10-3-072.

\section{Consent of publication}

All patients and healthy subject signed informed consent to participate in this study and to publish medical results.

\section{Availability of data and supporting materials section}

Please contact author for data requests.

\section{Authors Contribution}

S. van Hoeve: gait analysis, writing, submitting.

G. Stollenwerck: writing.

P. Willems: technical procedures/matlab/gait analysis.

A. Witlox: writing.

K. Meijer: data analysis.

M. Poeze: data analysis writing.

\section{Conflict of interest}

None of the authors have any financial and personal relationships with other people or organizations to disclose that could inappropriately influence their work.

\section{Role of the funding source}

There was no funding source for this study.

\section{References}

[1] Aitken A, Poulson D. Dislocation of the tarsometatarsal joint. J Bone Joint Surg 1963:45:246-60.

[2] Gotha HE, Lareau CR, Fellars TA. Diagnosis and management of lisfranc injuries and metatarsal fractures. Orthop Rehabil 2013;96(5):33-6.

[3] Kösters C, Bockholt S, Müller C, Winter C, Rosenbaum D, Raschke MJ, et al. Comparing the outcomes between Chopart, Lisfranc and multiple metatarsal shaft fractures. Arch Orthop Trauma Surg 2014;134(10):1397-404.

[4] Kuo RS, Tejwaini NC, Digiovanni CW, Holt SK, Benirschke SK, Hansen Jr. ST, et al. Outcome after open reduction internal fixation of Lisfranc joint injuries. J Bone and Joint Surg 2000;82(11):1609-18.

[5] Curtis MJ, Meyerson M, Szura B. Tarsometatarsal joint injuries in the athlete. J Sports Med 1993;21(4):497-502. 
[6] Granata JD, Philbin TM. The midfoot sprain: a review of Lisfranc ligament injuries. Phys Sportsmed 2010;38(4):119-26.

[7] Rosenberg GA, Patterson BM. Tarsometatarsal (Lisfranc's) fracture-dislocation. Am J Orthop (Belle Mead NJ) 1995:7-16.

[8] Bandac RC, Botez P. Lisfranc midfoot dislocations: correlations between surgical treatment and functional outcomes. Rev Med Chir Soc Med Nat Iasi 2012;116(3):834-9.

[9] Sheibani-Rad S, Coetzee JC, Giveans MR, DiGiovanni C. Arthrodesis versus ORIF for Lisfranc fractures. Orthopedics 2012;35(6):868-73.

[10] Chopra S, Rouhani H, Assal M, Aminian K, Crevoisier X. Outcome of unilateral ankle arthrodesis and total ankle replacement in terms of bilateral gait mechanics. J Orthop Res 2014;32(3):377-84.

[11] Khazzam M, Long JT, Marks RM, Harris GF. Kinematic changes of the foot and ankle in patients with systemic rheumatoid arthritis and forefoot deformity. J Orthop Res 2007;25(3):319-29.

[12] Alonso-Vázquez A, Villarroya MA, Franco MA, Asín J, Calvo B. Kinematic assessment of paediatric forefoot varus. Gait Posture 2009;29(2):214-9.

[13] Arampatzis A, Bruggemann GP, Klapsing GM. A three-dimensional shankfoot model to determine the foot motion during landings. Med Sci Sports Exerc 2002;34(1):130-8.

[14] Caravaggi P, Bennedetti MG, Berti L, Leardini A. Repeatability of a multisegment foot protocol in adult subjects. Gait Posture 2011;33(1):133-5.

[15] Carson MC, Harrington MG, Thompson N, O'Conner JJ, Theologis TN. Kinematic analysis of amulti-segment foot model for research and clinical applications: a repeatability analysis. J Biomech 2001:34:1299-307.

[16] Cornwall MW, McPoil TG. Three dimensional movement of the foot during the stance phase of walking. J Am Podiatr Med Assoc 1999;89(2):56-66.

[17] Cornwall MW, McPoil TG. Motion of the calcaneus, naviculair and first metatarsal during the stance phase of walking. J Am Podiatr Med Assoc 2002;92(2):67-76.

[18] Curtis DJ, Bencke J, Stebbins JA, Stansfield B. Intra-rater repeatability of the Oxford foot model in healthy children in different stages of the foot roll over process during gait. Gait Posture 2009;30(1):118-21.

[19] Houck JR, Tome JM, Nawoczenski DA. Subtalar neutral position as an offset for a kinematic model of the foot during walking. Gait Posture 2008;28(1):29-37.

[20] Kidder SM, Abuzzahab FS, Harris GF, Johnson JE. A system for the analysis of foot and ankle kinematics during gait. IEEE Trans Rehabil Eng 1996;4(1):2532.

[21] Leardini A, Bennedetti MG, Catani F, Simoncini L, Giannini S. An anatomically based protocol for the description of foot segment kinematics during gait. Clin Biomech 1999;14:528-36.

[22] Leardini A, Bennedetti MG, Berti L, Bettinelli D, Nativo R, Giannini S. Rear-foot, mid-foot and fore-foot motion during the stance phase of gait. Gait Posture 2007;25:453-62.

[23] MacWilliams BA, Cowley M, Nicholson DE. Foot kinematics and kinetics during adolescent gait. Gait Posture 2003:17(3):214-24.

[24] Rattanaprasert U, Smith R, Sullivan M, Gilleard W. Three dimensiona kinematics of the forefoot, rearfoot, and leg without the function of tibialis posterior in comparison with normal during stance phase of walking. Clin Biomech 1999;14:14-23.

[25] Sawacha Z, Cristoferi G, Guarneri G, Corazza S, Donà G, Denti P, et al. Characterizing multisegment foot kinematics during gait in diabetic foot patients. J Neuroeng Rehabil 200923(6).

[26] Simon J, Doederlein L, McCintosh AS, Mataxiotis D, Block HG, Wolf SI. The Heidelberg foot measurement method: development, description and assessment. Gait Posture 2006;23(4):411-24.

[27] Stebbins J, Harrington M, Thompson N, Zavatsky A, Theologis T. Repeatability of a model for measuring multi-segment foot kinematics in children. Gait Posture 2006;23(4):401-10.
[28] Tome J, Nawozcenski D, Flemister A, Houck J. Comparison of foot kinematics between subjects with posterior tibialis tendon dysfunction and healthy controls. J Orthop Sports Phys Ther 2006;36(9):635-44.

[29] Wilken J, Saltzman C, Yack. Validation of a multi-segment foot model. Summer Meeting 2004 American Orthopedic Foot and Ankle Society; Seattle.

[30] van Hoeve S, de Vos J, Weijers PHE, Verbruggen JPAM, Willems P, Poeze M, et al. Repeatability of the Oxford Foot Model for kinematic gait analysis of the foot and ankle. Clin Res Foot Ankle 20153(2).

[31] Wright CJ, Arnold BI, Pidcoe PE. Repeatability of the modified Oxford Foot model during gait in healthy adults. Gait Posture 2011;33(1):108-12.

[32] van Hoeve S, de Vos J, Verbruggen JPAM, Willems P, Meijer K, Poeze M. Gait analysis and functional outcome after calcaneal fractures. J Bone Joint Surg Am 2015;97(22):1879-88, doi:http://dx.doi.org/10.2106/JBJS.N.01279.

[33] Teng AL, Pinzur MS, Lomasney L, Mahoney L, Havey R. Functional outcome following anatomic restoration of tarsal-metatarsal fracture dislocation. Foot Ankle Int 2002;23(10):922-6.

[34] Wiss DA, Kull DM, Perry J. Lisfranc fracture-dislocations of the foot: a clinicalkinesiological study. J Orthop Trauma 1987:1(4):267-74.

[35] Hardcastle PH, Reschauer R, Kutscha-Lissberg E, Schoffmann W. Injuries to the tarsometatarsal joint. Incidence, classification and treatment. J Bone Joint Surg Br 1982;64(3):349-56.

[36] Myerson M. The diagnosis and treatment of injuries to the Lisfranc joint complex. Orthop Clin Norh Am 1989;20:655-64.

[37] Mulier T, Reynders P, Dereymaeker G, Broos P. Severe Lisfrancs injuries: primary arthrodesis or ORIF? Foot Ankle Int 2002;23(10):902-5.

[38] Smith N, Stone C, Furey A. Does open reduction and internal fixation versus primary arthrodesis improve patient outcomes for Lisfranc trauma? A systematic review and meta-analysis. Clin Orthop Relat Res 2016;474 (6):1445-52.

[39] Coetzee JC, Ly TV. Treatment of primarily ligamentous Lisfranc joint injuries: primary arthrodesis compared with open reduction and internal fixation. Surgical technique. J Bone Joint Surg 2007;89:122-7.

[40] Agostini V, Ganio D, Facchin K, Cane L, Moreira Carneiro S, Knaflitz M. Gait parameters and muscle activation patterns at 3, 6 and 12 months after total hip arthroplasty. J Arthroplasty 2014;29(6):1265-72.

[41] Nantel J, Termoz N, Vendittoli PA, Lavigne M, Prince F. Gait patterns after total hip arthroplasty and surface replacement arthroplasty. Arch Phys Med Rehabil 2009;90(3):463-9.

[42] Arnold JB, Mackintosh S, Jones S, Thewlis D. Differences in foot kinematics between young and older adults during walking. Gait Posture 2014;39(2):68994.

[43] Legault-Moore D, Chester VL, de Vries G. Multisegment foot kinematics during walking in younger and older adults. J Clin Med Res 2012;4(4):259-66.

[44] Van Hoeve S, Leenstra B, Verbruggen JPAM, Willems P, Poeze M, Meijer K. The effect of age and speed on foot and ankle kinematics assessed using a foursegment foot model. unpublished data.

[45] Grood ES, Suntay WJ. A joint coordinate system for the clinical description of three-dimensional motions. J Biomech Eng 1983;105:136-44.

[46] Wu G, Siegler S, Allard P, Kirtley C, Leardini A, Rosenbaum D, et al. ISB recommendation on definitions of joint coordinate system of various joints for the reporting of human joint motion - part I: ankle, hip, and spine. J Biomech 2002;35(4):543-8.

[47] Schepers T, Kieboom BC, van Diggele P, Patka P, Van Lieshout EM. Pedobarographic analysis and quality of life after Lisfranc fracture dislocation. Foot Ankle Int 2010;31(10):857-64.

[48] https://www.dssresearch.com/knowledgecenter/toolkitcalculators/samplesizecalculators.aspx. 04-2016 used. 